\title{
Mechanical properties of three-dimensional interconnected alumina/steel metal matrix composites
}

\author{
D. Wittig • C. G. Aneziris · T. Graule • \\ J. Kuebler
}

Received: 11 July 2008/ Accepted: 20 October 2008/Published online: 23 November 2008

(C) Springer Science+Business Media, LLC 2008

\begin{abstract}
Three-dimensional interconnected alumina/ steel metal matrix composites (MMCs) were produced by pressureless Ti-activated melt infiltration method using three types of $\mathrm{Al}_{2} \mathrm{O}_{3}$ powder with different sizes and shapes. By partial sintering during infiltration an interpenetrating ceramic network was realised. The effect of the ceramic particle size and shape on the resulting ceramic network, volume \% fraction and the MMC properties is presented. The MMCs were characterised for mechanical properties at room temperature and elevated temperature. An increase in flexural strength and Young's modulus with decreasing particle size has been observed. In addition, the effect of the volume of ceramic content and the surface finish of the MMCs on the wear behaviour is shown.
\end{abstract}

\section{Introduction}

Wear resistant and failure-tolerant metal matrix composites (MMCs) can be created by combining hard ceramics with ductile metals. With regard to the application of the MMCs as metal forming tools, a prolongation of the life time and the resultant reduced equipment downtimes are achieved. Furthermore, wear resistant MMCs are very interesting for

\footnotetext{
D. Wittig · T. Graule $\cdot$ J. Kuebler $(\bowtie)$

Empa, Swiss Federal Laboratories for Materials Testing and Research, Laboratory for High Performance Ceramics, Ueberlandstrasse 129, CH-8600 Duebendorf, Switzerland

e-mail: jakob.kuebler@empa.ch

\section{G. Aneziris}

Institute for Ceramics, Glass and Construction Materials,

Technical University Bergakademie Freiberg,

Agricolastrasse 17, 09596 Freiberg, Germany
}

machine parts in pharmaceutical and food industry applications since contamination is reduced due to higher wear resistance. In the past, wear resistant alumina particle/steel $\left(\mathrm{Al}_{2} \mathrm{O}_{3} / \mathrm{X} 38 \mathrm{CrMoV5}-1\right)$ - MMCs have already been produced by pressureless titanium-activated melt infiltration $[1,2]$. The current work deals with the in-situ fabrication of three-dimensional interconnected $\mathrm{Al}_{2} \mathrm{O}_{3}$ /steel-MMCs.

Metal matrix composites with an interpenetrating microstructure are interesting due to high stiffness and improved mechanical properties such as strength, fracture toughness and thermal shock resistance [3]. In contrast to MMCs reinforced by single separated particles, threedimensional interconnected MMCs have also potential for improved high-temperature properties and thermal stability in view of the high-temperature resistant ceramic network [4]. In terms of the wear behaviour MMCs with interpenetrating networks exhibit a greater wear resistance than MMCs with discontinuous ceramic reinforcement [5]. However, it has to be pointed out that the improved wear resistance of the matrix due to the ceramic reinforcement depends strongly on the test conditions, the microstructure and the properties of the individual phases [5].

There are different methods to produce three-dimensional interconnected MMCs such as hot pressing, pressureless sintering, direct oxidation of the metal and reactive metal penetration [6]. An attractive method is the metal melt infiltration of porous ceramic bodies [7]. To overcome the general poor wetting of ceramics by metal melts, which is a result of the primarily ionic and covalent bonds typical of ceramics (e.g. $\mathrm{Al}_{2} \mathrm{O}_{3}$ ), external pressures can be applied, e.g. mechanical (squeeze casting) or by gas (gas pressure infiltration) [8,9]. In addition the wetting of ceramics by metal melts can be improved by changing the chemistry of the metal/ceramic interface. Adding pure active metal particles such as titanium to the ceramic 
surface or distributing them directly in the ceramic preform enables the pressureless wetting of ceramics by metal melts $[10,11]$. The beneficial effect on wetting by titanium has been recognised for a long time. Due to the chemical reactivity of titanium with ceramic surfaces a modification of the metal/ceramic interface chemistry is caused; a TiO reaction layer is formed, whose metallic character has beneficial effects on wetting. By increasing the metallic character of the ceramics the wetting of ceramics by metal melts is improved [12]. Apart from titanium-activated pressureless infiltration, pressureless melt infiltration of a preform is possible by coating the ceramic particles with a metal layer or alloying appropriate metallic elements (e.g. Ti) to the metal phase $[13,14]$.

To produce interpenetrating MMCs by pressureless melt infiltration a porous ceramic is needed. There are different methods to produce porous ceramics (e.g. foaming of a ceramic slip, replication method, sol gel route) [6]. In the present study, three-dimensional interconnected $\mathrm{Al}_{2} \mathrm{O}_{3} /$ steel MMCs have been produced by in-situ partial sintering of $\mathrm{Al}_{2} \mathrm{O}_{3}$ powder compacts during the infiltration process. Three $\mathrm{Al}_{2} \mathrm{O}_{3}$ powders were used differing in size and shape and the MMCs were characterised for microstructure, mechanical properties (Young's modulus and strength at room temperature and elevated temperatures) and wear behaviour.

\section{Experimental}

Ceramic preforms were produced using three types of $\mathrm{Al}_{2} \mathrm{O}_{3}$ powder, elemental titanium (TiGd2, TLS Technik, Germany) and an organic binder (Optapix KG 1000, Zschimmer \& Schwarz, Germany). $\mathrm{An} \mathrm{Al}_{2} \mathrm{O}_{3}$ with globular particles (AA-18, Sumitomo, Japan), an $\mathrm{Al}_{2} \mathrm{O}_{3}$ with fine broken particles and an $\mathrm{Al}_{2} \mathrm{O}_{3}$ with coarse broken particles (WSK F360 and WSK 120, Treibacher Schleifmittel, Germany) were used. The density and the grain size of the particles were determined by He-pycnometry (AccuPyc 1330, micromeritics, USA) and laser diffractometry (Mastersizer X, Malvern Instruments, United Kingdom), respectively. The specific surface area was measured by the BET method (Coulter SA 3100, Beckman Coulter, USA). The data of the powder are presented in Table 1 .

The $\mathrm{Al}_{2} \mathrm{O}_{3}$ powder and $20 \mathrm{wt}$. \% Ti were combined with 2 wt. \% binder. The amount of binder is related to the total amount of dry powder (i.e. $\mathrm{Al}_{2} \mathrm{O}_{3}$ and Ti). Dry and wet homogenisation (by adding some de-ionised water to the powder mixture) was carried out in a ball mill. By pressing the powder mixture through a sieve $(1 \mathrm{~mm})$ granulates were formed. Subsequently, the preforms (plates of $50 \times 100 \times 10 \mathrm{~mm}$ and discs with a diameter of $55 \mathrm{~mm}$ ) were produced by uniaxial die pressing of granulates at
Table 1 Properties of starting powders used for MMC preform production

\begin{tabular}{lllrrrl}
\hline Material & $\begin{array}{l}\text { Purity } \\
(\%)\end{array}$ & \multicolumn{2}{l}{$\begin{array}{l}\text { Particle size distribution } \\
(\mu \mathrm{m})\end{array}$} & $\begin{array}{l}\text { Density } \\
\left(\mathrm{g} / \mathrm{cm}^{3}\right)\end{array}$ & $\begin{array}{l}\text { Specific } \\
\text { surface } \\
\text { area }\left(\mathrm{m}^{2} / \mathrm{g}\right)\end{array}$ \\
\cline { 3 - 5 } $\mathrm{d}_{10}$ & $\mathrm{~d}_{50}$ & $\mathrm{~d}_{90}$ & & \\
\hline AA-18 & $>99.9$ & 18 & 25 & 34 & 3.99 & 0.204 \\
WSK & 99.47 & 17 & 31 & 58 & 3.94 & 0.256 \\
F360 & & & & & & \\
WSK 120 & 99.78 & 97 & 155 & 245 & 3.95 & 0.055 \\
Ti & Grade 2 & 13 & 29 & 52 & 4.51 & 0.209 \\
\hline
\end{tabular}

different pressures (plate: $26 \mathrm{MPa}$ or disc: $55 \mathrm{MPa}$ ). The different microstructures of the pressed preforms are shown in Fig. 1. Finally, the preforms were dried in a drying cabinet $\left(24 \mathrm{~h}\right.$ at $\left.70{ }^{\circ} \mathrm{C}\right)$. The porosity of the preforms was investigated by He-pycnometry (AccuPyc 1330, Micromeritics, USA).

The pressureless activated metal melt infiltration was conducted in a vacuum furnace (Super VII, Centorr Vacuum Industries, USA) under high vacuum conditions (i.e. $1.4 \times 10^{-4}$ mbar). The preforms were infiltrated by the metal melt at a temperature of $1,600{ }^{\circ} \mathrm{C}$ and a dwell time of $4 \mathrm{~h}$. The MMC plates were machined to form specimen bars $(3 \times 4 \times \geq 45 \mathrm{~mm})$ for mechanical testing. In addition MMC discs for wear testing were prepared from the disc samples.

The Young's modulus at room temperature and elevated temperatures $\left(200,400\right.$ and $\left.600{ }^{\circ} \mathrm{C}\right)$ was investigated by impulse excitation method (IET-method). By using the resonance frequency, which was investigated with an adapted measuring system (Grindo Sonic MK5, J.W. Lemmen N.V., Belgium), and the geometric data of the specimen the Young's modulus was calculated. The four point strength tests were performed using a universal testing machine (Zwick 1478, Zwick GmbH \& Co., Germany) with a loading span of $20 \mathrm{~mm} / 40 \mathrm{~mm}$. The four point bending was carried out in accordance to EN 843-1 at room temperature and at the following elevated temperatures $\left(200,400,600,800\right.$ and $\left.1,000{ }^{\circ} \mathrm{C}\right)$. Therefore, the universal testing machine was equipped with a hightemperature furnace (Maytec, Germany). The deflection of the tensile surface over the $20 \mathrm{~mm}$ inner span was measured with transducers.

The fracture surfaces and the microstructure of the MMCs were investigated by SEM (LEO 1455, Zeiss, Germany with EDX). In addition, an optical microscope was used (Reichert-Jung, Austria). The densities of the specimens were acquired by Archimedes method (AG 204 Delta Range, Mettler Toledo, Switzerland).

The wear behaviour of the MMCs was characterised using a CSM Tribometer (CSM Instruments, Switzerland). 
Fig. 1 Fracture surfaces of preforms consisting of a coarse broken WSK 120, b fine broken WSK F360 and c globular AA-18 $\mathrm{Al}_{2} \mathrm{O}_{3}$ particles, Ti-particles (white particles) and binder

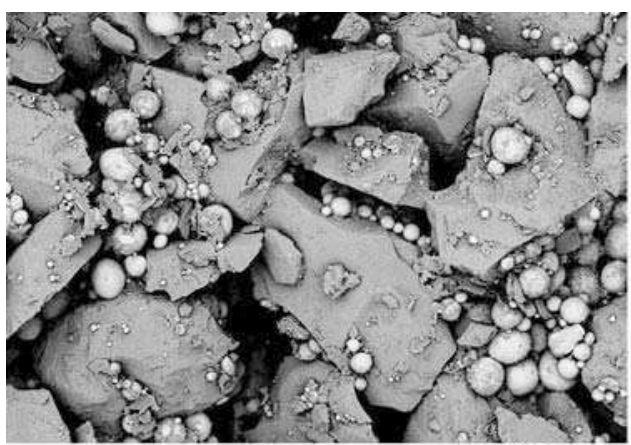

(a)

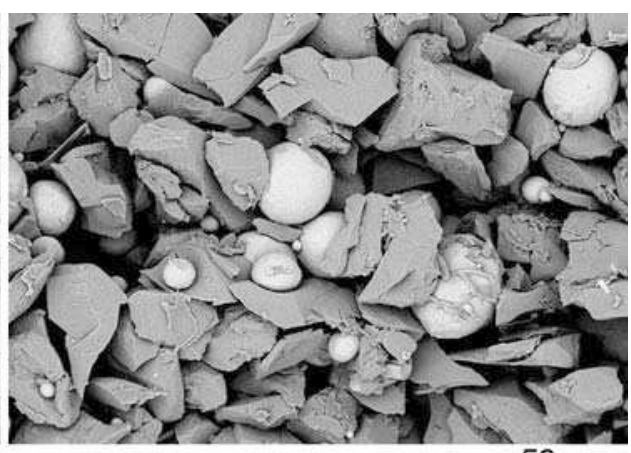

(b)

$50 \mu \mathrm{m}$
Dry sliding tests were carried out in air at a temperature of $24{ }^{\circ} \mathrm{C}$ and a relative humidity of $30 \%$ with a pin-on-disc

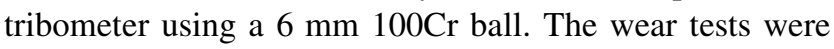
performed with an applied load of $5 \mathrm{~N}$ and a constant speed of $5 \mathrm{~cm} / \mathrm{s}$ for 30,000 laps in rotation mode with a radius of $20 \mathrm{~mm}$ (with a total distance of $942 \mathrm{~m}$ ). The surface roughness of the MMCs was determined using a Hommel T500 indicator (Hommelwerke, Germany).

\section{Results and discussion}

\section{Microstructure}

The microstructure of all MMCs consisted of $\mathrm{Al}_{2} \mathrm{O}_{3}$ particles and Ti-rich phases embedded in the metal matrix. The phases of the microstructure were inhomogeneously distributed. MMCs based on coarse $\mathrm{Al}_{2} \mathrm{O}_{3}$ powder (WSK 120) consisted of mainly single unconnected ceramic particles in the metal matrix (Fig. 2a). MMCs made from fine $\mathrm{Al}_{2} \mathrm{O}_{3}$ powder (WSK $\mathrm{F} 360$ and AA-18), respectively) possessed a non-continuous ceramic network created by partial sintering of the particles (neck growth) during infiltration (Fig. 2b-c). The partial sintering also resulted in closed porosity therefore non-infiltrated areas remain. To some extent the $\mathrm{Al}_{2} \mathrm{O}_{3}$ particles were corroded and degraded at the particle surface.

In the microstructure of the MMCs, Ti-rich phases were present and inhomogeneously distributed over the infiltration height as already reported by Lemster et al. [1]. The amount of Ti-rich phases increased from the bottom (i.e. the starting point of infiltration) to the top of the specimen due to the entrainment with the metal melt [1]. Ti-rich phases existed in the MMCs in different forms (Fig. 3). Qualitative EDX analysis indicated the Ti-rich phases at the interface of the $\mathrm{Al}_{2} \mathrm{O}_{3}$ particles and the steel matrix to be $\mathrm{TiO}_{\mathrm{x}}$ and $\mathrm{Ti}_{\mathrm{x}} \mathrm{O}_{\mathrm{y}} \cdot \mathrm{Ti} / \mathrm{Al}_{2} \mathrm{O}_{3}$ interactions resulted in the formation of $\mathrm{Ti}$ oxides. However, the oxidation of $\mathrm{Ti}$ due to remains of oxygen in the environment cannot completely be excluded. The Ti-rich phases also contained $\mathrm{Al}$ and other trace elements from the steel (Fe, $\mathrm{Cr}$ and $\mathrm{Si}$ ). Ti-rich phases with angular shape indicating the hexagonal crystal structure of elemental Ti were also found (Fig. 2c). These phases with a crystal structure consisted mainly of $\mathrm{Ti}$, and small amounts of $\mathrm{Fe}$ and $\mathrm{Cr}$. Some $\mathrm{Ti}$ was also found to have dissolved into the metal matrix. In general the matrix contained $\mathrm{Fe}, \mathrm{Cr}, \mathrm{Si}, \mathrm{Al}$, small amounts of $\mathrm{Ti}$ and traces of $\mathrm{V}$. The local enrichment of $\mathrm{Ti}$ and $\mathrm{Si}$ resulted in the formation of $\mathrm{Fe}(\mathrm{Ti}, \mathrm{Si})$. By slightly etching the microstructure with $3 \%$ nitric acid, the grain boundaries of the $\mathrm{Fe}(\mathrm{Ti}, \mathrm{Si})$ phase were highlighted (Fig. 3).

\section{Density}

The use of three $\mathrm{Al}_{2} \mathrm{O}_{3}$ powders differing in size and shape resulted in preforms varying in porosity therefore the density of the MMCs differs with the type of $\mathrm{Al}_{2} \mathrm{O}_{3}$ powder (Table 2). MMCs made from globular AA-18 have an average density of $5.64 \mathrm{~g} / \mathrm{cm}^{3}$. The ceramic fraction amounts to 47 vol\%. The globular particle shape allowed a 
Fig. 2 Microstructure of MMCs made with a coarse broken WSK 120, b fine broken WSK F360 and $\mathbf{c}$ globular AA-18 $\mathrm{Al}_{2} \mathrm{O}_{3}$ powder. The penetration of the $\mathrm{Al}_{2} \mathrm{O}_{3}$ particles by Ti-rich phases resulted in a degradation of particle surfaces
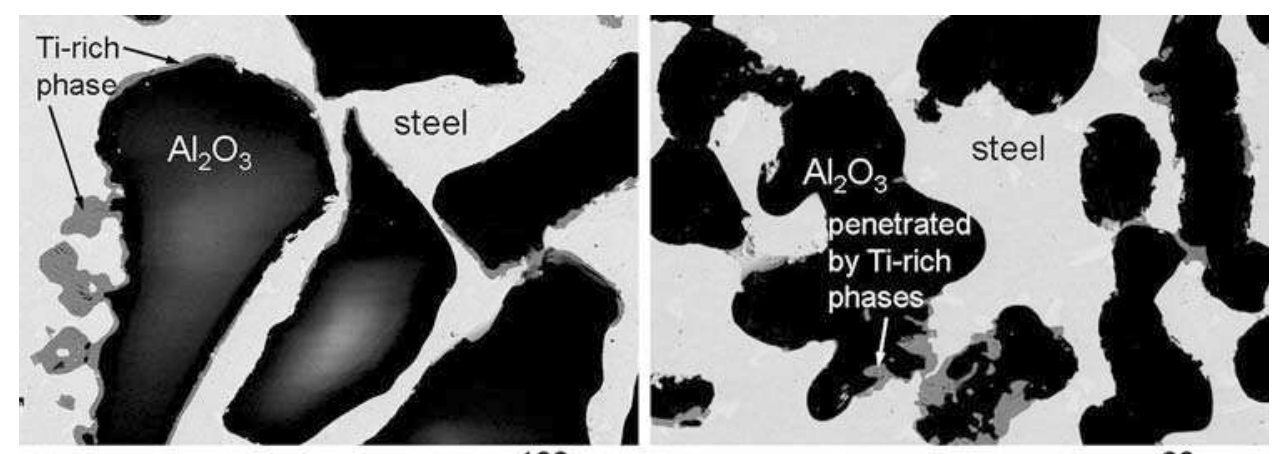

(a)

$100 \mu \mathrm{m}$

$30 \mu \mathrm{m}$

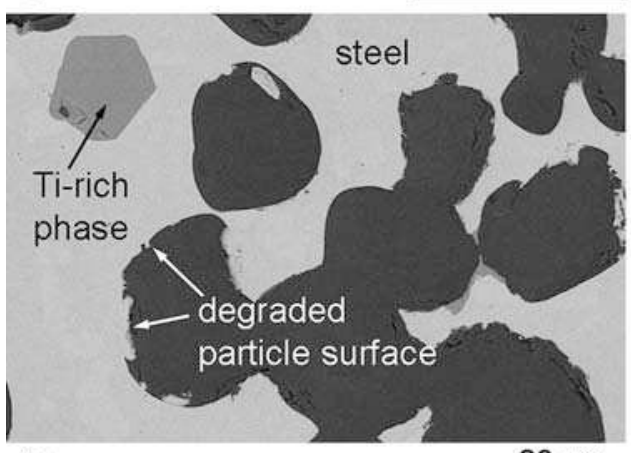

(c)

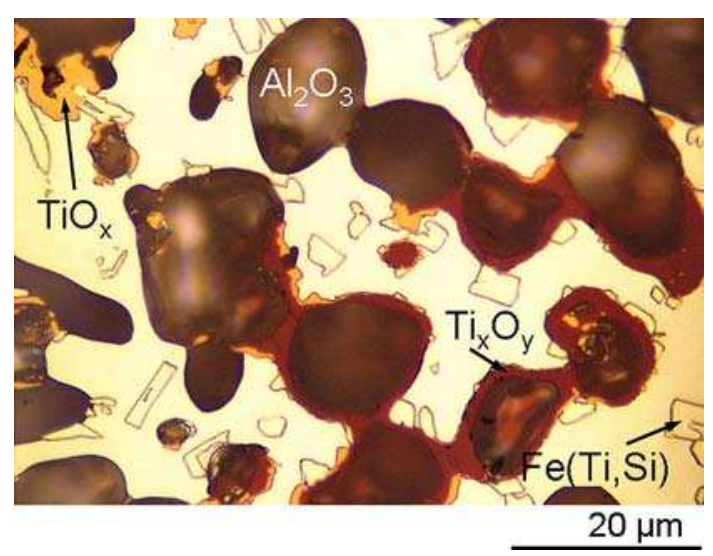

Fig. 3 Microstructure of an AA-18/steel-MMC showing different Ti-rich phases (optical microscope picture). By slightly etching of the microstructure the $\mathrm{Fe}(\mathrm{Ti}, \mathrm{Si})$ phase in the metal matrix were highlighted

Table 2 The effect of type of $\mathrm{Al}_{2} \mathrm{O}_{3}$ on some structural properties of the preforms of MMCs

\begin{tabular}{|c|c|c|c|}
\hline Type of $\mathrm{Al}_{2} \mathrm{O}_{3}$ & WSK 120 & WSK F360 & AA-18 \\
\hline Porosity of preform (vol\%) & 44 & 49 & 40 \\
\hline Density of the MMC $\left(\mathrm{g} / \mathrm{cm}^{3}\right)$ & 5.51 & 5.78 & 5.64 \\
\hline $\begin{array}{l}\text { Ceramic fraction of the MMC } \\
(\text { vol } \%)\end{array}$ & 44 & 40 & 47 \\
\hline
\end{tabular}

relative dense packing of the particles resulting in a porosity of only $40 \mathrm{vol} \%$. Whereas the non-uniform shape of the broken particles caused an increased porosity.
Preforms made of fine broken WSK F360 exhibited a porosity of $49 \mathrm{vol} \%$. The derived MMCs possess an average density of $5.78 \mathrm{~g} / \mathrm{cm}^{3}$ and a ceramic fraction of 40 vol\%. MMCs based on coarse broken WSK 120 show an average density of $5.51 \mathrm{~g} / \mathrm{cm}^{3}$ and a ceramic fraction of 44 vol\%, though the associated preforms possessed a porosity of $44 \mathrm{vol} \%$. However, residual pores in the MMCs lowered the density.

Young's modulus at room temperature

The Young's modulus at room temperature has been determined by IET-method. The average Young's modulus of the MMCs varied from 260 to $280 \mathrm{GPa}$ depending on the ceramic fraction of the MMCs. By increasing the ceramic fraction the Young's modulus is enhanced due to the higher Young's modulus of $\mathrm{Al}_{2} \mathrm{O}_{3}$ (typically $400 \mathrm{GPa}$ ). The steel X38CrMoV5-1 possesses a Young's modulus of $215 \mathrm{GPa}$. The MMCs based on globular AA-18 showed an average Young's modulus of $280 \mathrm{GPa}$ attributed to the ceramic fraction of $47 \mathrm{vol} \%$. The MMCs with a ceramic fraction of 44 and $40 \mathrm{vol} \%$ made from broken WSK 120 and WSK F360 had an average Young's modulus of 266 and $260 \mathrm{GPa}$, respectively.

The measured values are not between the upper E(u) and the lower $\mathrm{E}(\mathrm{l})$ bound calculated (theoretical) by the rules of mixture for a two phase composite [15] (Table 3). The calculation is based on an ideal infiltrated MMC with a ceramic content of between 40 and $47 \mathrm{vol} \%$ using the composition of the starting materials (i.e. $\mathrm{Al}_{2} \mathrm{O}_{3}$ and steel); 
Table 3 Measured and calculated Young's moduli of MMCs with different $\mathrm{Al}_{2} \mathrm{O}_{3}$ types

\begin{tabular}{llll}
\hline Type of $\mathrm{Al}_{2} \mathrm{O}_{3}$ & WSK 120 & WSK F360 & AA-18 \\
\hline $\mathrm{E}_{\mathrm{IET}-\text { method }}(\mathrm{GPa})$ & $266\left(_{-17}^{+16}\right)$ & $260\left(_{-8}^{+11}\right)$ & $280\left(_{-4}^{+7}\right)$ \\
$\mathrm{E}(\mathrm{u})_{\text {calculated }}(\mathrm{GPa})$ & 296 & 289 & 302 \\
$\mathrm{E}(\mathrm{l})_{\text {calculated }}(\mathrm{GPa})$ & 270 & 264 & 275 \\
\hline
\end{tabular}

Ti phases and phase transformations were neglected. The calculation was used as an estimation for the Young's modulus since the measured Young's moduli are affected by pores present in the MMCs which were not considered.

Flexural strength at room temperature

The flexural strength of the MMCs has been determined in accordance with EN 843-1 by four point bending without measuring the specimen deflection. Hence the given values are the nominal values and not the corrected true stress values. MMCs based on globular AA-18 possessed an average flexural strength of $516\left({ }_{-106}^{+89}\right) \mathrm{MPa}$, whereas the MMCs based on broken $\mathrm{Al}_{2} \mathrm{O}_{3}$ powder (WSK F360 and WSK 120) showed an average flexural strength of $451\left({ }_{-23}^{+39}\right)$ MPa and $335\left({ }_{-39}^{+31}\right) \mathrm{MPa}$, respectively. The particle size (i.e. Griffith criterion) and the lower interconnection of the ceramic particles resulted in the low flexural strength of the MMCs based on coarse broken WSK 120. The scatter of strength, especially of the MMCs made from globular AA-18, was comparatively high. A high scatter is normally due to there being more than one type of fracture origin and also due to significant variations in the size of fracture origin. Therefore, fractography has been carried out to determine the possible fracture origins. The tensile surfaces of the specimen were placed next to each other (as shown in Fig. 4) to allow easy location of the fracture origin as recommended in the fractography standard CEN/TS 843-6.

Porous areas differing in size and quantity on or near the tensile surface of the specimens (as shown in Fig. 4) acted as fracture origins and the deviating size of these were responsible for the scatter of strength data. Some closed porosity was created by partial sintering (neck growth) of the $\mathrm{Al}_{2} \mathrm{O}_{3}$ particles. In MMCs made with fine $\mathrm{Al}_{2} \mathrm{O}_{3}$ powder (WSK F360 and AA-18) single or continuous large porous areas (around 150-500 $\mu \mathrm{m}$ ) resulted in the lowest strength. Specimens with the highest strength exhibited smaller porous areas $(40-100 \mu \mathrm{m})$. In MMCs made from WSK 120 large single pores acted as the fracture origins (up to $950 \mu \mathrm{m}$ ). The MMCs showed a different crack propagation mechanism of failure depending on the type of $\mathrm{Al}_{2} \mathrm{O}_{3}$. In MMCs based on fine particles (WSK F360 and AA-18) crack propagation occurred through the particles (transgranular) and around the particles (intergranular), as shown in Fig. 5a-b.

During the intergranular failure the interconnections of the $\mathrm{Al}_{2} \mathrm{O}_{3}$ particles created by partial sintering (neck growth), cracked. Intergranular failure followed by crack deflection is seen as a result of the missing particle/matrix interface, whereas a strong particle/matrix interface results normally in transgranular cracking [16]. However, no clear $\mathrm{Al}_{2} \mathrm{O}_{3} /$ steel matrix interface has been found till now [1]. In MMCs based on coarse WSK 120, transgranular failure of the unconnected particles occurred (Fig. 5b). In terms of the particle size of the coarse $\mathrm{Al}_{2} \mathrm{O}_{3}$ transgranular cracking due to defects in the particles cannot be excluded. All MMCs exhibited occasionally single $\mathrm{Al}_{2} \mathrm{O}_{3}$ particles with cleavage structures (Fig. 5c). As slipping depends on the orientation of the ceramic crystal [16], the particles are randomly distributed and limited in number.

\section{Young's modulus at elevated temperatures}

The Young's moduli of MMCs made with different types of $\mathrm{Al}_{2} \mathrm{O}_{3}$ powder were determined at 200,400 and $600{ }^{\circ} \mathrm{C}$ with IET-method. The values are shown in Fig. 6. With increasing temperature up to $600{ }^{\circ} \mathrm{C}$ the Young's modulus of the MMCs decreased 15-16\% whilst the Young's modulus of the steel X38CrMoV5-1 was reduced by $24 \%$
Fig. 4 Tensile surfaces of MMCs made from globular AA-18 with porous areas, which acted as fracture origins and resulted in a the highest strength and $\mathbf{b}$ the lowest strength

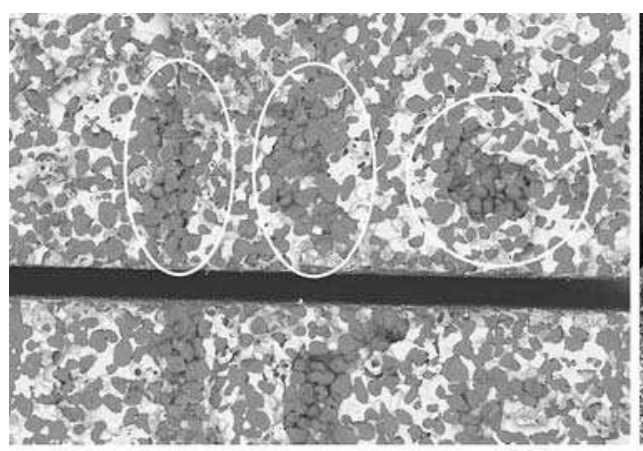

(a)
$200 \mu \mathrm{m}$

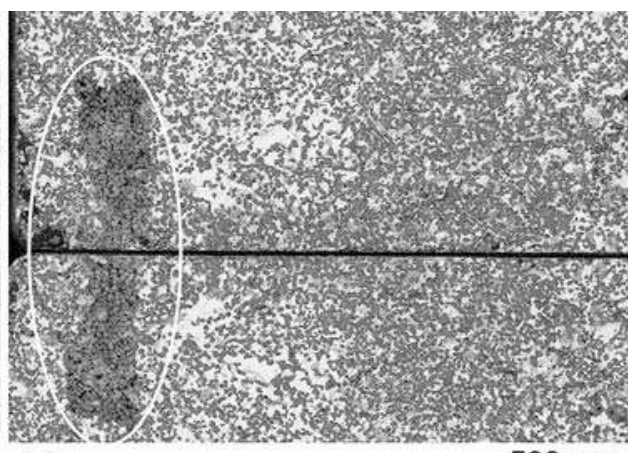

(b)
$500 \mu \mathrm{m}$ 
Fig. 5 Fracture surfaces of MMCs made with a globular AA-18 and b coarse broken WSK 120 exhibit intergranular (I), i.e. failure of neck, and transgranular (T) cracking, $\mathbf{c}$ occasionally cleavage occurred
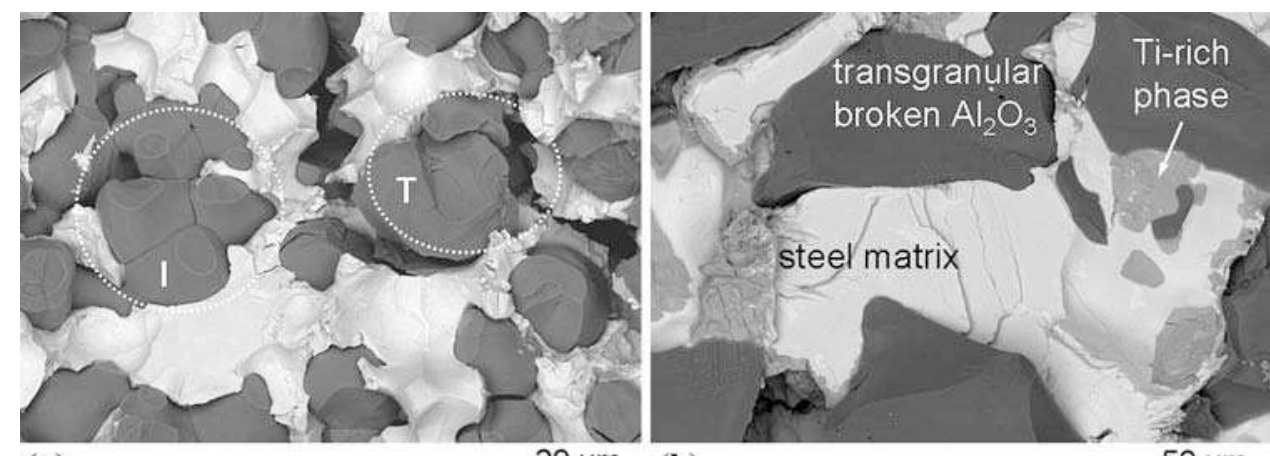

(a)

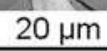

(b)

$50 \mu \mathrm{m}$

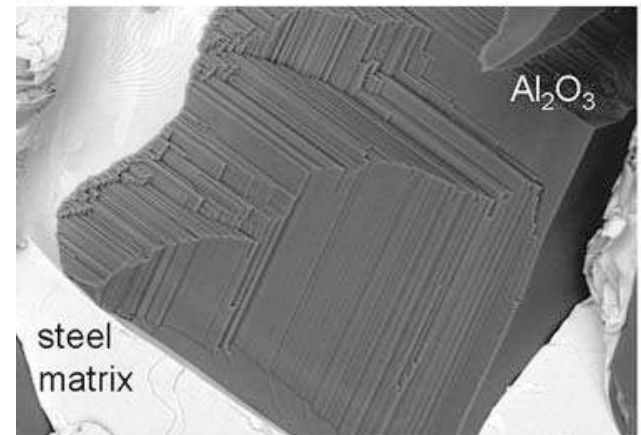

(c)

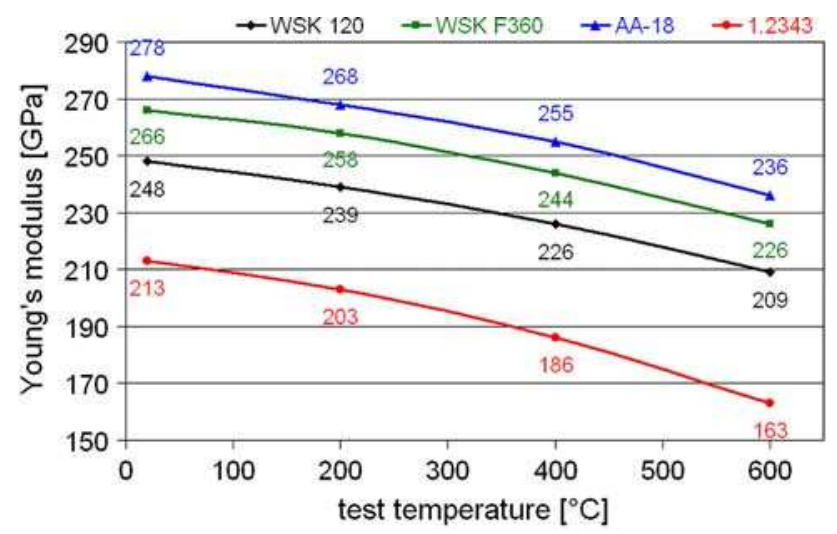

Fig. 6 Young's modulus of MMCs made from different $\mathrm{Al}_{2} \mathrm{O}_{3}$ powder (WSK 120, WSK F360 and AA-18) at elevated temperatures determined by IET-method

compared to the room temperature values. The lower decrease in stiffness of the MMCs was primarily due to the ceramic particle reinforcement. The more interconnected the ceramic particles were, the higher the measured Young's modulus was (Fig. 6). The Young's moduli of the MMC made from AA-18 investigated by IET-method can be compared to the values determined by linear regression the true stress/true strain plot. The Young's modulus of the later method with $281 \mathrm{GPa}$ at $20{ }^{\circ} \mathrm{C}, 255 \mathrm{GPa}$ at $400{ }^{\circ} \mathrm{C}$ and 240 at $600{ }^{\circ} \mathrm{C}$ correspond to the values given in Fig. 6 . The values of the two testing methods correlate well differing by less than $2 \%$.
Flexural strength at elevated temperatures

The $\mathrm{Al}_{2} \mathrm{O}_{3} /$ steel-MMCs have been tested at elevated temperatures by four point bending. The numbers of the specimens were limited to one specimen for each temperature $\left(20,200,400,600,800\right.$ and $\left.1,000{ }^{\circ} \mathrm{C}\right)$. Using the raw data true stress-true strain curves were calculated as proposed by Gogotsi and Lugovy [17]. The stress $\sigma_{t r}$ and the strain $\varepsilon$ in the outer layer of the specimens were determined using the following equations:

$\sigma_{t r}=\frac{2 a}{b h^{2}}\left(P+\frac{\delta}{2} \frac{\mathrm{d} P}{\mathrm{~d} \delta}\right), \varepsilon=\frac{4 h}{L^{2}} \delta$

where $P$ is the load and $\delta$ is the deflection and $L$ is the length of the deflector span $(20 \mathrm{~mm})$, respectively. $a$ is the mean of the distance between centres of the inner and the outer support rollers $(10 \mathrm{~mm}) . b$ and $h$ are the width and the height $h$ of the specimen, respectively. The curves will not be discussed in detail due to the limited amount of specimens.

The true stress-true strain curves of the MMCs exhibited a linear elastic behaviour region for temperatures up to $600{ }^{\circ} \mathrm{C}$ (obeying Hooke's law) and non-linear behaviour prior to failure. The graphs are presented in Fig. 7. Most metals deform plastically prior to fracture, whereas technical ceramics show elastic behaviour followed by fracture without significant plastic deformation (at room temperature and low temperatures). The non-linearity in the stressstrain curves of the MMCs prior failure is due to the plastic 

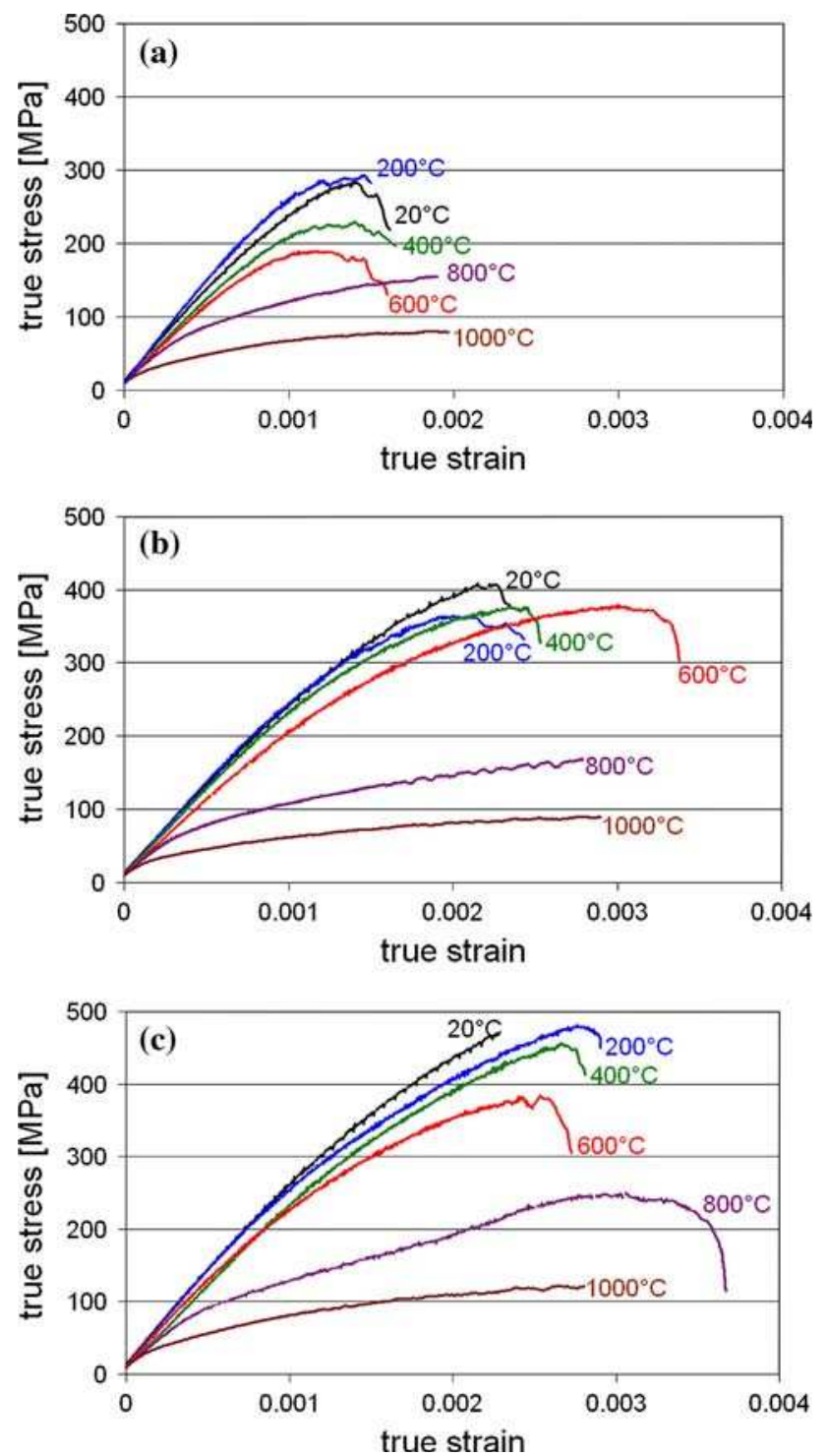

Fig. 7 True stress-true strain curves of MMCs based on a coarse broken WSK 120, b fine broken WSK F360 and c globular AA-18 $\mathrm{Al}_{2} \mathrm{O}_{3}$ powder showing non-linear behaviour prior to failure

deformation of the metal matrix. However, it cannot be excluded that some of the non-linearity/plastic deformation may be due to the formation of internal micro-cracks in the MMCs. The curves obtained at $800{ }^{\circ} \mathrm{C}$ and $1,000{ }^{\circ} \mathrm{C}$ showed a non-linear progress; a linear range was difficult to determine or at least very small. Above $600{ }^{\circ} \mathrm{C}$ the curves start to exhibit features (i.e. primary and secondary creep) often observed in creep curves (e.g. Fig. 7c). With increasing temperature softening of the metal matrix occurred. The heating of the specimens can also result in a relaxation of the thermal residual stresses inherent in the MMCs caused by the thermal mismatch of the metal matrix and the ceramic reinforcement.
The high temperature strength of MMCs with interconnected ceramic particles (MMCs made with AA-18 and WSK F360, respectively) exceeded the high temperature strength of the MMCs with loose $\mathrm{Al}_{2} \mathrm{O}_{3}$ particles in the matrix (MMCs based on WSK 120). The linear region (Hooke's law) of WSK 120/steel-MMCs is less than the WSK F360/steel-MMCs and AA-18/steel-MMCs.

In addition further measurements have been done at selected temperatures to clarify the results of the MMCs based on globular AA-18. Therefore, five specimens were tested at room temperature, 400 and $600{ }^{\circ} \mathrm{C}$. The elevated temperatures were chosen due to the maximum operating temperature of the steel X38CrMoV5-1 $\left(450-500{ }^{\circ} \mathrm{C}\right)$ used as the matrix phase. The average true stress at fracture at room temperature $\left(495_{-35}^{+34} \mathrm{MPa}\right)$ and $400{ }^{\circ} \mathrm{C}\left(489_{-39}^{+33} \mathrm{MPa}\right)$ were only slightly different. Whilst the true stress at $600{ }^{\circ} \mathrm{C}$ $\left(425_{-82}^{+79} \mathrm{MPa}\right)$ has decreased. As previously mentioned the scatter of the data is due to porous areas at the tensile surface differing in size and quantity.

Wear

The wear behaviour of the $\mathrm{Al}_{2} \mathrm{O}_{3}$ /steel-MMCs has been carried out by pin-on-disc tests. The dry sliding wear of the MMCs against a steel ball $(100 \mathrm{Cr})$ has been tested two times, with two different surface finishes on the MMC discs. Using a diamond cutting wheel (type D126-C100) and an $\mathrm{Al}_{2} \mathrm{O}_{3}$ grinding wheel (type 64A46H15VP), respectively for the MMC test specimen preparation resulted in two different surface finishes.

In the first test the MMCs with a higher surface roughness were tested (Table 4). The coefficient of friction of the MMCs made from broken $\mathrm{Al}_{2} \mathrm{O}_{3}$ powder (WSK 120, WSK F360) was 0.72. The MMC based on globular AA-18 showed a slightly lower coefficient of friction of 0.67 . Due to the abrasive ceramic particles in the metal matrix, worn diameters of the pins were created (Table 4). In the second test the coefficient of frictions were enhanced about $15 \%$ for the AA-18/steel-MMCs, respectively $24 \%$ for the WSK F360/steel-MMCs. The finer surface finish $(0.15 \mu \mathrm{m})$ resulted in an increased contact area between the ceramic particles and the pin, hence friction and abrasive wear of the pin have been increased (Table 4). The MMC made with coarse broken WSK 120 showed a similar coefficient of friction (0.73) in both of the tests as a result of the large particle size $\left(\mathrm{d}_{50}\right.$ of $\left.155 \mu \mathrm{m}\right)$. The friction coefficients of the $\mathrm{Al}_{2} \mathrm{O}_{3}$ /steel-MMCs were lower than the coefficient of friction of the steel X38CrMoV5-1, which was 1.00 . With the incorporation of the hard, wear resistant $\mathrm{Al}_{2} \mathrm{O}_{3}$ particles in the steel matrix, the friction was reduced. 
Table 4 Coefficient of friction of MMCs with different $\mathrm{Al}_{2} \mathrm{O}_{3}$ powders depending on the surface finish (before testing)

\begin{tabular}{|c|c|c|c|c|c|c|}
\hline \multirow[t]{2}{*}{$\mathrm{Al}_{2} \mathrm{O}_{3}$} & \multicolumn{3}{|l|}{ 1. Test } & \multicolumn{3}{|l|}{ 2. Test } \\
\hline & $\begin{array}{l}\text { Roughness } \\
(\mu \mathrm{m})\end{array}$ & $\begin{array}{l}\text { Coefficient } \\
\text { of friction }\end{array}$ & $\begin{array}{l}\text { Worn diameter } \\
\text { of the pin }(\mu \mathrm{m})\end{array}$ & $\begin{array}{l}\text { Roughness } \\
(\mu \mathrm{m})\end{array}$ & $\begin{array}{l}\text { Coefficient } \\
\text { of friction }\end{array}$ & $\begin{array}{l}\text { Worn diameter } \\
\text { of the pin }(\mu \mathrm{m})\end{array}$ \\
\hline AA-18 & 0.44 & 0.67 & 2,679 & 0.14 & 0.77 & 2,785 \\
\hline WSK F360 & 0.51 & 0.72 & 2,676 & 0.15 & 0.89 & 3,208 \\
\hline WSK 120 & 0.83 & 0.72 & 2,838 & 0.41 & 0.73 & 2,816 \\
\hline
\end{tabular}

\section{Conclusions}

Interpenetrating $\mathrm{Al}_{2} \mathrm{O}_{3}$ /steel-MMCs are in-situ producible by pressureless activated melt infiltration method of porous green bodies. The ceramic network created by partial sintering of fine $\mathrm{Al}_{2} \mathrm{O}_{3}$ particles resulted in increased flexural strength at room temperature (up to 35\%) and at elevated temperatures in spite of the fact, that the highest density has not been achieved. The particle size and especially the shape dominate according to the strength values. MMCs made from globular $\mathrm{Al}_{2} \mathrm{O}_{3}$ powder possessed the highest strength values due to the particle shape. Failure was caused by porous areas differing in size and quantity, whereas the MMCs possessed plastic deformation prior to failure.

The Young's modulus determined at room temperature and elevated temperatures is mainly affected by the ceramic fraction of the MMCs. Due to the different ceramic fractions of the MMCs depending on the type of $\mathrm{Al}_{2} \mathrm{O}_{3}$ powder (and pores in the microstructure) no explicit conclusion concerning the impact of the ceramic network can be made on Young's modulus. However, the reduction of Young's modulus as result of elevated temperature has been demonstrated.

The wear behaviour of the failure-tolerant MMCs is affected by the particle size, the ceramic content of the MMC and the surface roughness. Interconnected ceramic particles may reduce the breaking out of particles; however, the ceramic network is not essential for a low coefficient of friction.

Although some effects of decreasing $\mathrm{Al}_{2} \mathrm{O}_{3}$ particle size can be observed, it is clear that the large pores observed in fractography have to be eliminated during the infiltration process. These pores are due to the granulation process used. Therefore, future work will be done to enhance the quality of the $\mathrm{Al}_{2} \mathrm{O}_{3} /$ steel-MMCs by improving the processing (e.g. the granulation process).

Acknowledgements The authors would like to thank R. Bächthold and Dr. G. Blugan at Empa, Materials Science and Technology, Switzerland as well as T. Minghetti and C. Schelle at RUAG Components, Switzerland for their contributions to this work.

\section{References}

1. Lemster K, Graule T, Kuebler J (2005) Mater Sci Eng A393:229

2. Lemster K, Graule T, Minghetti T, Schelle C, Kuebler J (2006) Mater Sci Eng A420:296

3. Travitzky NA, Claussen N (1992) J Eur Ceram Soc 9:61

4. Zhou W, Hu W, Zhang D (1999) Mater Lett 40:156

5. Imbeni V, Hutchings IM, Breslin MC (1999) Wear 233-235:462

6. Clarke DR (1992) JACS 75:739

7. Skirl S, Krause R, Wiederhorn SM, Rödel J (2001) JACS 84:2034

8. Huber T, Degischer HP, Lefranc G, Schmitt T (2006) Compos Sci Technol 66:2206

9. Xing H, Cao X, Hu W, Zhao L, Zhang J (2005) Mater Lett 59:1563

10. Kajikawa Y, Nukami T, Flemings MC (1995) Metall Mater Trans A 26A:2155

11. Lemster K, Delporte M, Graule T, Kuebler J (2007) Ceram Int 33:1179

12. Li JG (1994) Ceram Int 20:391

13. Chen J, Hao C, Zhang J (2006) Mater Lett 60:2489

14. Farid A, Shi-ju G (2006) Trans Nonferrous Met Soc China 16:629

15. Callister WD (2003) Materials science and engineering: an introduction. Wiley, New York

16. Brooks CR, Choudhury A (2002) Failure analysis of engineering materials. McGraw-Hill, New York

17. Gogotsi G, Lugovy M (2001) Theor Appl Fract Mech 36:115 